\title{
MODEL OF COMMUNICATION USABLE FOR SMALL AND MEDIUM-SIZED COMPANIES FOR THE CONSUMER COMMUNICATION IN SOCIAL MEDIA
}

\author{
Otakar Ungerman, Světlana Myslivcová
}

\section{Introduction}

Social media are among the fastest developing Internet marketing tools, and more and more Internet users connect to it every day. With regard to the ever-growing amount of various social media, there is a lot of ambiguity regarding how company representatives should approach them. Therefore, it is important to understand a way how various types of social media function. At the same time, based on understanding, determine how to use such media for as efficient creation of business opportunities as possible and for increase of head start on competition. If they are utilized correctly, they can become the best mechanism that can be utilized when building a brand, product awareness, or increase of revenues. Rapid growth of activities in social media represents an opportunity, as well as a challenge. Opportunity lies in the possibility to utilize correct marketing procedures in social media and encouragement of growth of entrepreneurial activities. Challenge rests in time demand necessary to "crack a code" that will enable to utilize social networks efficiently and effectively. The study reacts to lack of information on possible utilization of social media for communication with consumers for small and medium companies. On one hand, there is a lot of publications related to marketing communication issues. Communication models that analyze this relationship in a lot of detail have been created to connect consumers and businesses. On the other hand, models of communication using social media elaborated in detail do not exist. This missing part of the marketing communication was a reason for carrying out the primary research that is presented in this study.

The main objective of the study rested in researching social media based on the primary and secondary research and create a communication model that can be utilized by small and medium companies. In order to achieve the overall intent of the study, the main objective was decomposed into two partial objectives:

- Objective A: Map the current situation in communication between consumers and companies carried out using social media.

- Objective B: Identify factors that influence communication methods and define importance of communication attributes that affect it.

The concept framework shown (Fig. 1) has the descending tendency. The upper part is derived from secondary sources. The lower part consists of the primary research.

The concept framework is compiled so that it identifies attributes that affect communication of small and medium companies with consumers. The whole concept leads to the main objective, which is compilation of the communication model for social media.

\section{Literature Overview}

Social media have currently become an important communication channel in all countries where the Internet is freely accessible. It is illustrated by data specifying a number of users of the largest social network, Facebook, in the Czech Republic. In June 2012, the number already reached 3.7 million residents. In the world-wide 


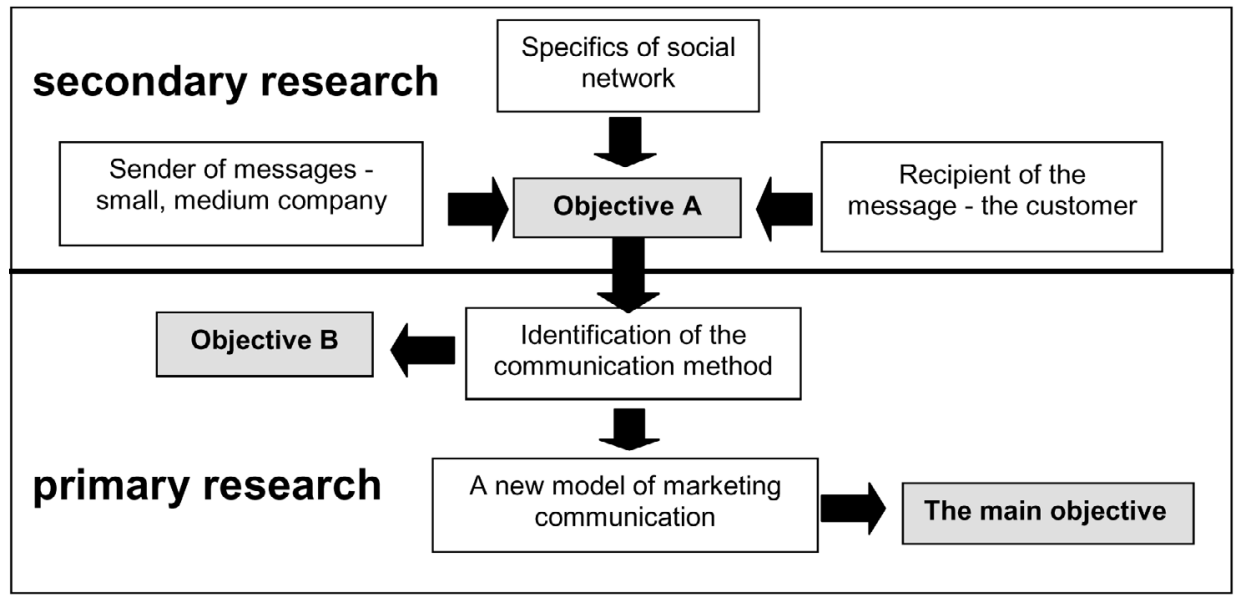

Source: own

scale, Facebook by itself has 950 million users [29]. However, Facebook is not all the social media, but there is a lot of international and local media types that are created or cease to exist at any given time. For example, the largest Asian network, "QQ", has more than 850 million [12] users.

Social media in general are considered a powerful tool for companies to keep in touch with customers and acquire feedback from them. They can also maintain contact with their customers through the fan groups or promote their events. Not only companies, but even products can be promoted or have their fan groups there. On the other hand, bad reputation of a company spreads through Social media even faster [33], [14]. Social media can be characterized as a subset of media using the Internet connection. This type of media is sometimes referred to as the "new media" or "media 2.0." [19]. The exact definition of social media has been time-developing, and it can be characterized in various ways. Bouda [3] characterizes them as follows: "Social media enable communication that is not targeted such as in case of traditional media. Social media are built on interaction among people. Feedback from the public in the form of comments or editing of original texts or contents is the key element." Victoria Bush [4] offers another interesting definition: "Social media provide simple use of collaborative work areas with utilization of various communication tools". Scoble [25] expresses his opinion on social media in a novel way: "Traditional media are not as fast as social media in rectifying published errors - errors can be rectified immediately or pointed up immediately in a blog. It is not possible to immediately communicate via traditional media or comment to their contents, contrary to comments in blogs. Traditional media do not have their archives currently and easily accessible, contrary to blog archives". Definition [27] is interesting and fitting, "A social medium is any Internet medium where a group of like-minded people can meet and discuss certain topics". If definitions of social media are summarized, they can be defined as online media where contents are created and also shared by users.

The reason why the model of communication has been designed chiefly for small and medium-sized businesses is especially the opportunity to fight against large multinational companies. In the area of social media unlike other mass media (television), money is not as much decisive, but here it is an activity, an idea or process that makes decisions. Social media help to create a level playing field for all and provide small and medium-sized businesses access to larger markets through cost-effective promotion. This phenomenon is especially pronounced in the Czech Republic, where small and medium-sized businesses represent 
more than half the country's annual revenue and employ $62 \%$ of employees. At the same time the small and medium-sized companies in social media face certain problems. In that process six typical problems were detected that may slow down the introduction of Internet communication. These problems were: unclear communication strategy, new communication paradigms, non integrating marketing communication, and the company's involvement in Internet challenge, organizational changes, and people' skills in Internet communication [35], [2]. To increase competition factors in small and medium-sized business activities SME paid attention to the analysis of real conditions in a small enterprise aimed at the use of communication system as support for business activities. The determination of the concept of information demands, their tactics, methods, tools, and rules as well as decisions to use social network more effectively are the basic points of the information process analysis. Small and Medium-sized Enterprises turned our attention to monitor currently applied rules and tactics and according to them they should provide an answer to processes and activities used in the analyzed enterprise [23].

The main objective of information activity in marketing is communication with the consumer. Each observation can only become information provided that it is communicated, i.e. it passes through an arbitrary communication act or process. These communication acts can be expressed graphically by means of modelling. Modelling is one of the main methods of of studying the complex phenomena of the real world where all phenomena are related to each other and it is practically impossible to give their overall and accurate description. The model makes possible to depict objective reality in a simple way and capture only those aspects of the phenomenon that are considered important, i.e. that are close to the purpose for which the model has to fulfill. Necessarily, there happens a certain idealization of a particular phenomenon and its abstraction, which should not be confused with creating a copy of the modelled object or phenomenon, or a logical tautology. Communication models can be divided into one-way and multi-shift. One-way are mostly traditional models. In the traditional communication process, a sender relays a message through a channel to a receiver. The social marketers act as the sender or gatekeeper of information. This is referred to as vertical or top-down communication. The consumers, as the receivers, play a less active role. The channels, or means by which a sender transmits a message to the receiver, vary depending on the communication purpose, the intended receiver, and the type of message. Traditional communication channels include print, TV, broadcast, outdoor or personal [15]. The multidirectional communication models are those where consumers become creators and senders of messages. Consumers have always talked about an organization and its products with or without organizational leaders' or gatekeepers' consent.

And although word-of-mouth marketing is not new [36], emerging technologies and Web 2.0 social media applications have made it easier for messages to go "viral" at a faster pace. Therefore, social marketers must be proactive and strategic in using word-of-mouth or viral marketing as part of promotional strategies [31]. This model has several implications for social marketing practitioners. First, embracing the multi-directional models has the potential to reemphasize the consumer centered focus of social marketing. Consumers will be at the center of the communication process because they are both senders and creators of information. Second, social marketers must develop evaluation plans that include metrics for measuring the impact of communication and promotion. Most metrics related to print and broadcast communication channels are process in nature, measuring gross impressions [30].

\section{Methodology}

The research process consists of five phases. As the first step, there were established the research methods, next the research purpose, the respondent selection methods, the data collection methods and the data evaluation methods were the last step.

1. Methodology - from the methodology aspect, quantitative as well as qualitative methods were applied during the research. Both research methods were applied in succession. Qualitative methods preceded quantitative methods [16].

2. Research purpose - with respect of the study's objectives, it is possible to identify in the research the exploration purpose that 
directly explores an extent of importance attributed to a consumer and also the descriptive purpose that maps the current situation [24].

3. Selection of respondents - the "random quota sampling" method was carried out via social networks and the Internet. The population consisted of social media users over 13 on the territory of the Czech Republic. The total of 603 respondents participated in two primary stages of the research.

4. Data collection methods were adjusted to objectives and evaluation methods so that they would ensure validity of acquired data. Validity, which can also be interpreted as reliability, represents verification that the scientific method was selected correctly. Applied data collection methods:

- Dual group interview - a group interview or discussion; it belongs to the so-called qualitative research. At the group interview, visualization, associative and projective technique and role playing are used to discover relationships, attitudes, feelings, behaviors and motivations of consumers. Direct contact and inducing a certain social situation affect positively the expression of spontaneous, uncontrolled subjective reactions. The modified method called "dual group interview", which was used in the work, represents using multiple moderators for each data collection. Thus, the smooth progress of discussion is ensured.

- Group observation - observation is one of the basic methods of data collection although it is often underestimated. It is an indirect data collection instrument that does not require direct contact with the respondent. The advantage is that the researcher does not need the consent of the respondent to cooperate. This applies especially in case that the respondent does not want to cooperate or if the respondent is a company that resists co-operation. The keystone of observation is deliberate, purposeful and planned monitoring of ongoing reality without the observer's active intervening. Observation is used mainly in combination with other methods of data collection, especially with inquiries. Observations must have a certain scenario, in order to avoid distortion. The basis of observation is an accurate statement of the objective, which is needed to find out.

- Electronic inquiries - interviewing is based on direct or mediated contact between the researcher and the respondent. This contact is prepared in advance of the already identified issues. This serves to unify the conditions for processing the results. According to the specifics of the research, the intended method of questioning is determined. Electronic polling is the latest method based on the Internet. This method of questioning was conducted by e-mail, web pages and using social media. The advantage of electronic interviewing is the ability to target a certain group of respondents with relatively low costs.

5. Data evaluation methods were derived from the research objective and the type of researched data. Acquired data was evaluated using the " $R$ " mathematical software and the "Statgraphics 16 statistical program. Evaluation methods can be divided into the following groups:

- Nominal variables - as for nominal variables, qualitative sequence of the individual phenomena occurrences is not determined, thus there is not a relation of better-worse type between the individual values. An example is the representation of respondents in each age group. The group "30-39 years" is not qualitatively different from the group "13-19 years" or "40-49". At nominal variables, it is determined whether there is a statistically significant difference in the representation of pairs of individual categories of variables on the level of statistical significance, using the "pearson c2 test". Further, the pvalue is calculated which determines what error can be made when rejecting the hypothesis $\mathrm{HO}$.

- Ordinal variables - are variables that can take a finite number of values in a given interval and can be sorted according to qualitative terms. An example is the overall satisfaction rate 
which may gain integer values in the range $\langle 1,7\rangle$, where 1 is the best and 7 the worst. For better explanatory power, the values can be aggregated into three groups $\langle 1,3\rangle-$ satisfied, $<4>-$ neutral, $<5,7>-$ unhappy.

- Cardinal variables - are numeric variables whose values have the significance of numbers. It is possible to line them up in ascending or descending line, and they can take theoretically any value from the definition variables interval. When they are analyzed, at first the basic descriptive statics is performed with the calculation of the basic parameters of location, dispersion and skewness. Next, the verification of basic assumptions of homogeneity and normality is carried out. If the basic assumptions are granted, the links between individual files are examined. It is either rejection or nonrejection of the null hypothesis $\mathrm{HO}$ by the set of t-tests. In case of rejection of normality by Shapiro-test at its significant distortion the nonparametric Wilcoxon test is used. In the work, unless stated otherwise, the operating level of significance is $a=0.05$.

- Factor analysis - focuses on the analysis of the structure of internal relations among a large number of variables using a smaller set of latent variables, called factors. The aim was to summarize and reduce variables, with minimal loss of information. In order to conduct the factor analysis, Bartlett's test of sphericity and the condition of Kaiser-Meyer-Olkin (KMO) had to be met. Bartlett's test of sphericity tested the correlation among the original characters, i.e. that there is no correlation. $\mathrm{KMO}$ rate is the index of the comparison of the size of experimental correlation coefficients to the sizes of partial correlation coefficients. The evaluation result shows that: $\mathrm{KMO}$ » 0.9 marked great, $\mathrm{KMO}$ » 0.8 high, KMO » 0.7 medium, $\mathrm{KMO} \gg 0.6$ low, $\mathrm{KMO} \gg 0.5$ bad. If $\mathrm{KMO}$ is less than 0.5 , the correlation was unacceptably low, and therefore the factor analysis is inappropriate.

For the purpose of better interpretation of the data, the rotation of factors was performed (i.e. redistribution of explained variance for each factor). For the rotation there was chosen orthogonal varimax rotation method since the goal was to reduce the number of original variables and, in addition, it was empirically proven that varimax creates stress that can be explained easily. When interpreting the factors, it started from the load factor which was represented by the correlation coefficient between the original variable and factor. Correlations greater than \pm 0.5 were considered significant. If the variables did not reach the stated values, they were discarded and the analysis was carried out once again, or several times until the correlation coefficients of all the variables reached the minimum value \pm 0.5 . The aim of this procedure was to obtain the optimal number of variables. Acquired factors were named by variables tracks [18].

As for the data validation, reliability was used which indicates the reliability of measurement. The measurement reliability focuses on stability and conformity of the results obtained. The most commonly used indicator of reliability is Cronbach's alpha, which is a statistical method of detecting the degree level, degree of internal consistency and the reliability. It takes values ranging from 0 to 1 , while the value of 0.7 or more indicates a high consistency and reliability [22].

\section{Current State Analysis}

Contents of the first partial Objective A were: Map the current situation in communication between consumers and companies carried out using social media. This objective was fulfilled using the current state analysis. Secondary research published in foreign media will be used for the analysis. We were unable to uncover any relevant research dealing with the researched topic in the Czech Republic.

Social media are online media based on continuous mutual communication. When consumers use online media, they substitute traditional offline search by Internet-based search [13]. Besides facilitating the low-cost search, online media also provide display advertising via banners. Banner advertising presents visual and textual information about the brand, occupies approximately $10 \%$ of the computer monitor's area, and allows consumers to access the company's website when clicked on [34]. Some studies investigate the 
effectiveness of banner advertising [28], [10], [17]. Although its click-through rates are small, banner advertising creates a trace of ad exposure at pre-attentive levels of information processing, enhancing advertising and brand recalling [6]. According to Hollis [9], who analyzed 1,239 campaigns in the Adlndex database, the correlation between online ad awareness and purchase intent is 0.439 , suggesting that online advertising builds attitudinal equity of a brand similar to traditional media. Thus, companies can build brands using online media [9].

It is possible to incorporate social media into the model of communication by using 4 steps:

1. Setting the target segment for which the communication is directed.

2. Determining the reasons for which the company wants to cooperate with the audience.

3. Introducing a specific strategy that builds on the defined reasons.

4. Choosing technology which corresponds with the given strategy and also coincides with the choice of socially relevant applications [7], [32].

According to the research company Euromonitor International from 2012, which is a world leader in strategic research for consumer markets, social networking has quickly become a cornerstone of modern life, especially among the modern youth, and the Survey results reflect this trend. Less than $5 \%$ of Quick Pulse respondents claimed not to use social media at all. Other respondents prefer to use these resources to stay in touch with friends both local $(72 \%)$ and abroad $(79 \%)$, or to reconnect with old friends (68\%). Most also share photos $(69 \%)$ or seek out news $(64 \%)$. However, in addition to interacting with friends and acquaintances, some of our analysts interact with brands online. More than a third reported using social media to learn more about a certain product or service, or to read reviews or ask friends for advice (36-38\%). Many also use social media for the purpose of following companies or brands they like (26\%), and nearly that number $(23 \%)$ seek discounts and deals from those companies. A few also reported sharing such discounts with friends (10\%) or writing their own reviews (9\%). As the use of social media grows and as e-interaction with companies becomes more commonplace, these numbers are only likely to increase [8].
The basic research outputs follow:

a) None of the existing communication model proposes the universal solution utilizable for social media. If all the communication models are summarized, it is possible to reach the conclusion that communication models cannot be used for all social media. Reasons why none of the already compiled communication models can be used are as follows:

- Models are intended for social networks only, which is only a subset of all social media.

- Found communication models are intended for all types of companies; contrary to that, our research was focused on small and medium companies only.

b) The general norm of behavior of companies in social media was compiled from the secondary research. Compliance with the norm guarantees a good approach to social media. Three basic areas of communication in social media were generated at the conclusion.

- The first area focuses on criteria applied by successful companies in social media. Such criteria are arranged hierarchically. They are getting attention, inducing cooperation, attaining a user, uncovering preferences, and creating a permanent relationship [5].

- The second area focuses on principles of company communication, which are directness, expeditiousness, and accessibility [26].

- The third area consists of 10 identified rules that form behavior barriers, which companies should observe in social media [20]. These rules are listening, targeting, quality, patience, interconnection, influence, appreciation, accessibility, reciprocity, and the value principle.

If companies comply with this norm, there is a good assumption that their communication will lead to success.

c) The following results were derived from research carried out by foreign agencies and companies on the territory of the European Union:

- The main reasons for using social media are as follows: Lifestyle, services, business activity, family, and friends [21]. 
- Prevalence of personal communication over commercial communication was unambiguously proved [11].

- A customer perceives reasons of communication in social media completely differently than a company [11].

- There are differences in age composition and quantity of users in individual types of social media [1].

\section{The Main Achieved Results}

The primary research of communication in social media represented the second partial Objective B: Identify factors that influence communication methods and define importance of communication attributes that affect it. Graphical illustration is shown in Fig. 3.

\section{Fig. 3: Schematic research segmentation}

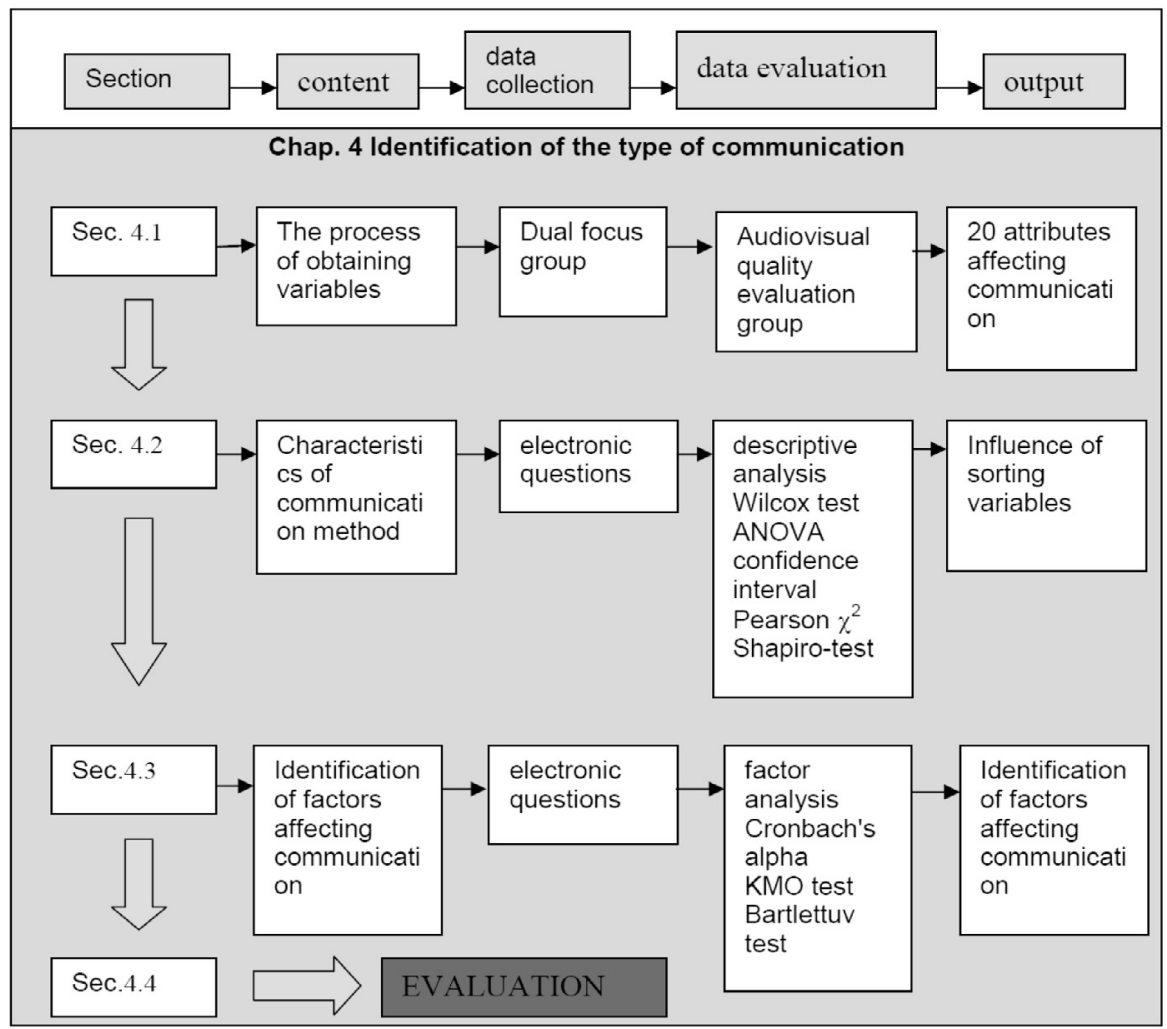

Source: own

This chapter's structure was divided into three main parts. The first part, Section 4.1, identifies attributes influencing communication in social media. The second part, Section 4.2, groups these attributes using statistical methods. The last part, Section 4.3, describes how the research led to the factor analysis whose objective rested in identification of factors influencing communication in social media.

\subsection{Variable Acquisition Process}

Research via a group interview was carried out in March 2012 with groups of respondents selected in advance. The data collection plan was adjusted to objectives and the method of data collection so that it secures required information in the appropriate way. The data collection plan gave answers to questions as to when, where, who, and whom the research 
would concern. Group interviews were executed in two days with the total of 48 respondents divided in five age groups: 13-19, 20-24, 25-29, 30-39, and 40 and above. A number of participants in one group was set as $7-11$ persons. For orientation purposes, duration of questioning was set as an hour and a half, based on the number of questions. The place of information collection was set with regard to a presentation possibility and especially a possibility to record the interviews. A research team consisting of five persons was formed for the purpose of data collection. The whole debate was led by a moderator who asked appropriate questions developing the whole issue. Other two team members encouraged discussion by stating their opinions and solution proposals. The remaining two members ensured interview recording and for that purpose, operated the corresponding equipment. Age intervals in the groups were defined based on the specified distribution of Facebook users, in which every group represents $20 \%$ of social media users.

There was a great emphasis on correct evaluation of data from the qualitative research. The team that participated in evaluation consisted of social media and marketing experts and a psychologist. Evaluation of acquired data was carried out in two phases. Outputs from the dual group interview were specified separately for each group in the first phase. Five partial tables with the resulting attributes were produced. Subsequently, a data synthesis into the final 20-attribute form took place: Speed of response to my question, Individual approach of the company, Online company communication all day long, Regular updates of information, The veracity of the information provided, Clarity of information provided, Humorous form of information, Qualification of provided information, Lotteries, contests, coupons from companies to SM, Complaint processing, Obtaining information for SM through advertising, Index of corporate information to social media, The way of providing information to social media, Presentation in Czech, Corporate social responsibility (environment, ethics), Supporting not-for-profit events (cultural, sports), Link to the company's website, Acquiring solicited information only, Obtaining integral and complete information, Communication through forums (chat).
The objective was fulfilled, the attributes were identified. Results may be used as recommendation how to communicate with customers. Differences, as well as similarities that connect all the age groups are apparent from group results. The list of the total 20 attributes could be utilized for compilation of a market strategy; however, it would be very complicated. The resulting attributes only define which variables influence customers. However, they do not show the scope of their influence and above all, they do not show if they influence them positively or negatively. For that purpose, it was necessary to subject the variables to further examination via statistical analyses.

\subsection{Characteristics of the Communication Method}

Research via electronic inquiring in social networks and the Internet was carried out in May 2012. The electronic questionnaire contained five questions where the first one dealt with assigning importance to twenty attributes uncovered in the previous research. Respondents were provided with a possibility to assign importance to these attributes by means of the 7-point scale where $1=$ the maximum importance and $7=$ the maximum unimportance. The remaining four questions were for the classification purposes only, and they were establishing: Sex, age, education, and economic activity. The total of 555 completed questionnaires were submitted for analysis. Questionnaires were excluded if they were incomplete or contained logical incoherence.

a) Evaluation of variables unaffected by classification parameters is shown in Tab. 1, in which attributes for assigning importance are classified based on the average, from the most important to the least important. Based on the resulting values, researched attributes can be divided into four groups. Based on indication of confidence intervals containing the mean value it is apparent that the following attributes have the best evaluation rating: Veracity and clarity of provided information, which forms the first group with the average evaluation rating approximately of the value of 2 . The second group contains attributes that do not exceed evaluation rating in the value of 3 : Acquiring of integral and complete information, regular information updates, speed 
of response, acquiring solicited information only, qualification of provided information, presentation in Czech, connection to the company's website. The third group consists of attributes with the average evaluation rating: The company's individual approach, corporate social responsibility, a way of providing information in social media, online communication all day long, contents of company information in social media, support of not-for-profit events, communication via a forum. The last group consists of attributions with evaluation rating exceeding 4: Humorous form of information, acquiring information for social media through advertisement, lotteries, contests, coupons.

\section{Tab. 1: Evaluation of the main variables unaffected by classification parameters}

\begin{tabular}{l|c|c|c|c|c} 
Evaluated attributes & $\overline{\mathbf{x}}$ & Median & $\overline{\mathbf{x}}-\mathbf{t} \frac{\mathbf{s}}{\sqrt{\mathbf{n}}}$ & $\overline{\mathbf{x}}+\mathbf{t} \frac{\mathbf{s}}{\sqrt{\mathbf{n}}}$ & $\begin{array}{c}\text { Standard } \\
\text { deviation }\end{array}$ \\
\hline Veracity of provided information & 2.04 & 1 & 1.898 & 2.182 & 1.702 \\
\hline Comprehensibility of provided information & 2.056 & 2 & 1.932 & 2.179 & 1.48 \\
\hline $\begin{array}{l}\text { Acquiring of integral and complete } \\
\text { information }\end{array}$ & 2.314 & 2 & 2.176 & 2.451 & 1.65 \\
\hline Regular information updates & 2.413 & 2 & 2.273 & 2.552 & 1.671 \\
\hline Speed of response & 2.497 & 2 & 2.366 & 2.629 & 1.576 \\
\hline Acquiring solicited information only & 2.569 & 2 & 2.431 & 2.708 & 1.662 \\
\hline Qualification of provided information & 2.634 & 2 & 2.506 & 2.762 & 1.537 \\
\hline Presentation in Czech & 2.659 & 2 & 2.513 & 2.806 & 1.762 \\
\hline Connection to the company's website & 2.834 & 2 & 2.693 & 2.976 & 1.698 \\
\hline Company's individual approach & 3.077 & 3 & 2.931 & 3.224 & 1.752 \\
\hline Corporate social responsibility: & 3.306 & 3 & 3.166 & 3.447 & 1.687 \\
\hline Method of providing information in SM & 3.312 & 3 & 3.169 & 3.455 & 1.716 \\
\hline Online communication all day long & 3.342 & 3 & 3.197 & 3.487 & 1.739 \\
\hline Contents of company information in SM & 3.559 & 3 & 3.425 & 3.692 & 1.606 \\
\hline Support of not-for-profit events & 3.649 & 4 & 3.502 & 3.795 & 1.76 \\
\hline Communication through a forum & 3.699 & 3 & 3.547 & 3.851 & 1.821 \\
\hline Processing complaints via social media & 4.047 & 4 & 3.886 & 4.207 & 1.927 \\
\hline Humorous form of information & 4.247 & 4 & 4.099 & 4.395 & 1.779 \\
\hline Information for SM from advertisement & 4.587 & 5 & 4.435 & 4.74 & 1.829 \\
\hline Lotteries, contests, coupons & 5 & 6 & 4.848 & 5.152 & 1.825 \\
\hline
\end{tabular}

Source: own calculation

b) For evaluation of the main variables affected by classification parameters, an analysis of influence of individual identification parameters was carried out. The analysis was carried out via the one-factor variance analysis. Based on executed tests, it is possible to say that differences in perception of communication methods by respondents exist across the demographic groups. Age, education, and sex play the main role. Demographic groups where statistically significant difference was identified (Tab. 2) were submitted to the analysis. 
Tab. 2: Distribution of respondents for the factor analysis

\begin{tabular}{c|c|c|c} 
Sex & Age & Education & Economic activity \\
\hline \multirow{2}{*}{ Male/female } & $13-29$ years & High School or less & Economically active \\
\cline { 2 - 4 } & 30 and above & Vocational school or college & Economically inactive \\
\hline
\end{tabular}

Source: own calculation

Upon further examination of difference variables, no significant differences were identified between the sexes. As for the other three classification parameters where statistically significant differences were identified, respondents were always divided into two groups. That significantly simplified division. Created groups were internally homogenous and mutually heterogeneous, which formed the prerequisite for further research (see the next section).

\subsection{Identification of Factors Influencing Communication}

Since the objective of Section 4.3 rested in identification of factors influencing the manner of communication, results were further processed via the factor analysis. This section focuses on determination of attributes that were really important for respondents and summarizes them into a smaller number of factors. In the first instance, the factor analysis was evaluated via the varimax method on all answers, regardless the classification variable. Evaluation based on demographic factors, for which statistically significant difference was detected, followed.

\subsubsection{Overall Evaluation of All Respondents} The factor analysis was carried out in total of four phases because the first analysis (or the second and third) identified attributes with the correlation coefficient value lower than \pm 0.5 , which were then excluded. This procedure's objective rested in reduction of variables and extracted factors to so-called optimum level, i.e. to a number of factors that affect communication with a customer the most. Table 3 is summarizing results of the factor analysis's four stages.

\section{Tab. 3: Factor analysis results for all respondents}

\begin{tabular}{|c|c|c|c|c|c|}
\hline & & 1. phase FA & 2. phase FA & 3. phase FA & 4. phase FA \\
\hline \multicolumn{2}{|l|}{ Cronbach's alpha } & \multicolumn{4}{|c|}{0.83028} \\
\hline \multicolumn{2}{|l|}{$95 \%$ interval of confidence } & \multicolumn{4}{|c|}{$0.80970 ; 0.85087$} \\
\hline \multicolumn{2}{|c|}{ Kaiser-Meyer-Olkin (KMO) measure } & 0.855 & 0.857 & 0.835 & 0.812 \\
\hline \multirow{3}{*}{ Bartlett's Test of Sphericity } & chi-square & $4,453.9$ & $3,098.9$ & $2,800.1$ & $2,374.3$ \\
\hline & degrees of freedom & 190 & 78 & 66 & 45 \\
\hline & significance level & 0 & 0 & 0 & 0 \\
\hline \multicolumn{2}{|c|}{ The number of variables entering the factor analysis } & 20 & 13 & 12 & 10 \\
\hline \multicolumn{2}{|l|}{ Number of factors } & 9 & 4 & 4 & 3 \\
\hline \multicolumn{2}{|c|}{ The number of variables in the factor } & 13 & 12 & 10 & 10 \\
\hline \multicolumn{2}{|c|}{ Cumulative percentage of variability } & 62.7 & 58.2 & 60.7 & 60 \\
\hline
\end{tabular}

Source: own calculation

Cronbach's alpha is met, and it unambiguously exceeds the value of 0.7 . The value of 0.83028 means high consistency and reliability, thus meeting the conditions for interpretation. The confidence interval content is valid, since the interval is $(0.80970-0.85087)$. The condition for achieving the Kaiser-Meyer-Olkin measure, i.e. the $\mathrm{KMO}$ value exceeding 0.5 was met in all phases. Rating of the first phase is "high" 0.86 , rating of the second phase is "high" 0.86 , rating of the third phase is "high" 0.84 , and rating of the fourth phase is "high" 0.81 . Bartlett's test of sphericity was met for all phases. The resulting matrix after the four steps is presented in Table 4. 
The resulting factor analysis matrix

\begin{tabular}{l|c|c|c} 
variables & Factor $\mathbf{1}$ & Factor $\mathbf{2}$ & Factor $\mathbf{3}$ \\
\hline Regular information updates & 0.702 & -0.076 & 0.233 \\
\hline Veracity of provided information & 0.877 & -0.129 & 0.17 \\
\hline Comprehensibility of provided information & 0.824 & -0.115 & 0.079 \\
\hline Lotteries, contests, coupons & -0.213 & 0.714 & 0.014 \\
\hline Processing complaints via social media & 0.074 & 0.625 & 0.119 \\
\hline Acquiring information for social media from advertisement & -0.137 & 0.752 & 0.133 \\
\hline Contents of company information in social media & 0.154 & 0.283 & 0.844 \\
\hline Method of providing information in social media & 0.291 & 0.048 & 0.756 \\
\hline Acquiring solicited information only & 0.635 & -0.022 & 0.058 \\
\hline Acquiring of integral and complete information & 0.666 & -0.049 & 0.199 \\
\hline percentage of variability & 29.70 & 15.90 & 14.50 \\
\hline Cumulative \% of the variability & 29.70 & 45.50 & 60.00 \\
\hline
\end{tabular}

Source: own calculation

When choosing the number of factors, there was chosen a combination of the two. The first approach was a graphical representation of the "screening" test, where a choice of three factors resulted from the position of the inflection point of the curve. The second way was "an appropriate interpretation of factors", in which it is necessary to build meaningful items so that they can be classified into a single concept factor. Here, only solutions with three factors were appropriate. Thus, three spheres of resulting factors were obtained from the factor analysis (Fig. 4), which were named based on the topic associated with the individual attributes:

- Information quality.

- Communication tools.

- Contents and method of providing information.

\section{Fig. 4: Resulting determination of variables for all respondents}

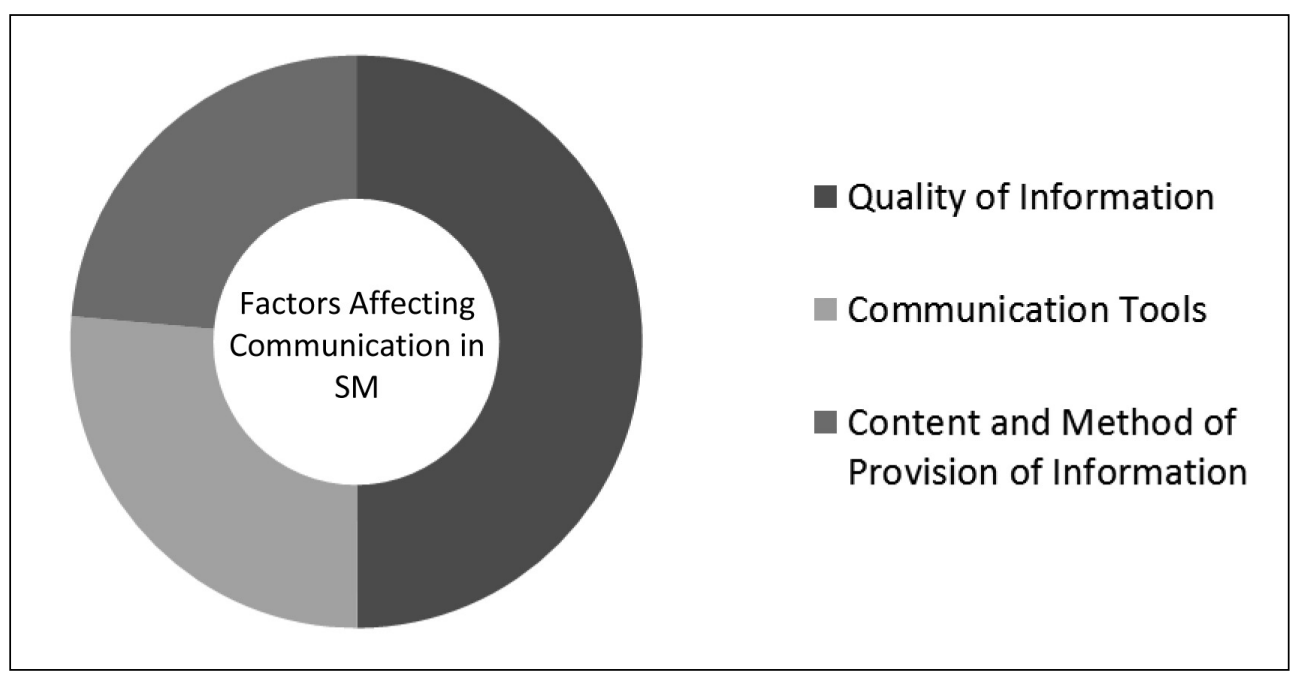


The first factor named as quality of information associates five variables that amount to $30 \%$ of the cumulated $60 \%$ variability. All five variables have a certain relation to information quality embedded. Regular updates imply importance of every-day upgrades of shared information. Veracity and clarity of information directly leads to the quality of communication. Acquiring of solicited and complete information also leads to the quality of communication. Respondents make it clear that quality of information is their main requirement.

The second factor named as communication tools associated three variables: Lotteries, contests, coupons provided by companies in social media, complaint processing in social media, and obtaining information in social media through advertisement amounts to $16 \%$ variability. Based on the results, it is apparent that communication tools have to be taken into account.

The third factor named a content and method of provision of information consists of two variables. Both the variables explain 14\% variability. After thorough analysis, it has not been possible to define a common hidden denominator. In this case, information content, as well as method of provision of information plays the important role and the factor is named after them.

\subsubsection{Evaluation of Factors Affecting Methods of Communication in Social Media}

The same factor analysis was applied to other six homogenous groups identified based on classification parameters with statistically significant differences. Results of evaluation in the individual demographic groups of respondents are shown in Fig. 5.

\section{Fig. 5: Resulting factors affecting communication in social media divided based on respondent groups}

\begin{tabular}{|c|c|c|}
\hline \multicolumn{3}{|c|}{$\begin{array}{l}\text { All respondents } \\
\text { - Quality of information } \\
\text { - Communication tools } \\
\text { - Content and Method of Providing Information }\end{array}$} \\
\hline $\begin{array}{l}\text { Age } \mathbf{1 3} \text { - } \mathbf{2 9} \text { years } \\
\text { - Quality of information } \\
\text { - Communication tools } \\
\text { - Content and Method of } \\
\text { Providing Information } \\
\text { - Flexibility in approach } \\
\text { - Social engagement }\end{array}$ & $\begin{array}{l}\text { Max. secondary } \\
\text { education } \\
\text { - Quality of information } \\
\text { and expertise } \\
\text { - Content and Method of } \\
\text { Providing Information } \\
\text { - Social engagement } \\
\text { - Communication tools }\end{array}$ & $\begin{array}{l}\text { Economically inactive } \\
\text { - Quality of information } \\
\text { - Communication tools } \\
\text { - Contents and Method of } \\
\text { Providing Information } \\
\text { - Social engagement }\end{array}$ \\
\hline $\begin{array}{l}\text { Age } 30 \text { and more years } \\
\text { - Quality and speed of } \\
\text { information } \\
\text { - Communication tools } \\
\text { - Social engagement } \\
\text { - Content and Method of } \\
\text { Providing Information }\end{array}$ & $\begin{array}{l}\text { College and university } \\
\text { education } \\
\text { - Quality of information and } \\
\text { expertise } \\
\text { - Communication tools } \\
\text { - Content Method of } \\
\text { Providing Information } \\
\text { - Social engagement }\end{array}$ & $\begin{array}{l}\text { Economically active } \\
\text { - Quality, speed and } \\
\text { professionalism of } \\
\text { information } \\
\text { - Communication tools } \\
\text { - Contents and Method of } \\
\text { Providing Information } \\
\text { - Social engagement }\end{array}$ \\
\hline
\end{tabular}

Source: own elaboration

1 FA: Quality of information - this factor appears in all respondent groups, even though sometimes in certain modifications. The factor was identically named for the group of 13-29 year old economically inactive respondents. In the age group 30 and above, there is the speed of providing information attribute present, in addition to quality of information. For two groups of respondents with the High School education or less and the vocational school or college 
education, the qualification of provided information appears together with the quality. For the only "economically active" group of respondents, the following attributes appear: Information quality, qualification, and speed of its provision. In evaluation of variability, this factor is always the first. Its percentage representation in the total variability is from $20 \%$ to $30 \%$. The reason the factor's name being "quality of provided information" is clearly hidden implicit meaning in all contained variables.

2 FA: Communication tools - is the second most important factor of the overall evaluation. This factor placed the second based on the variability size also in all other groups of respondents, with the exception of the group with High School education or less. This factor is extensive, and it is subject to further research in the following section. The absolute variability range for this factor's individual groups is from $10 \%$ to $16 \%$. Contained variables that clearly identify communication tools are the reason for its name.

3 FA: Contents and method of providing information - is the third factor. This factor places the third in the majority of respondent groups divided based on demographic groups. The absolute variability range is from $9.5 \%$ to $13.5 \%$ across all groups. Two absolutely independent variables contained in this factor are the reason for its ambiguous name.

4 FA: Social engagement - is the fourth factor affecting communication in social media. This factor did not appear in the analysis of the whole sample of respondents; however, it was always described in the analysis based on the demographic classification elements. In all cases, it consisted of two identical variables. The absolute variable range was from $8 \%$ to $12 \%$ in all demographically divided groups. The reason for this factor's name rests in engagement in the non-commercial sphere of contained attributes.

5 FA: Flexibility in approach - this factor was described by only one group of respondents divided based on the classification parameters, and it was the 13 to 29 age group. It consists of three variables, and its absolute variability is $9.5 \%$. This factor is unique and utilizable for this age group only. The reason for the name was hidden behind independent variables that are overall connected by variability.

\section{Communication Model}

The main objective of this study rested in proposal of a communication model for utilization by small and medium companies in the social media environment. Using synthesis, all the results were summarized into a new communication model (Fig. 6).

In the proposed communication model using social media, it is possible to define neither the beginning, nor the end. The whole model is based on the continuous information circulation. The initial impulse for utilization of social media can occur in the company if it decides to utilize this method of communication with a customer. Or, contrary to that, the company can be forced to enter into it as a result of the company's environment. The pressure can be generated by the micro-environment, as well as the macro-environment. Building a relationship between the company and a customer is the basis of the whole communication model. In the communication model, this relationship is proposed in its upper part.

After realizing an impulse initiated by the company or a customer, selection of the social media type follows, and it is the model's first part. Based on the secondary research, social media were already divided into seven subgroups, based on the communication tactics. Selection of one or more types of social media, which the company wishes to utilize, follows. It is ideal to begin with one medium and gradually add other types. The research confirmed that connection between individual types of social media also plays a certain role.

After selection of the social media type, selection of a communication tool, which is the model's second part, follows. This factor is very extensive as for its contents. Social media users prefer new forms of communication, such as mobile, buzz, viral, guerilla, and engagement marketing. These new tools are complemented with sales support, to which respondents assigned high importance. These tools are recommended for utilization in social media.

Contents creation forms the third part of the communication model. This part was specified based on the factor analysis result. Two identified factors are connected in this point. High-quality message is the first factor, and it has also been the strongest factor of the research. Information content was the second factor. Combination of all factors produced 


\section{Fig. 6: Communication model}

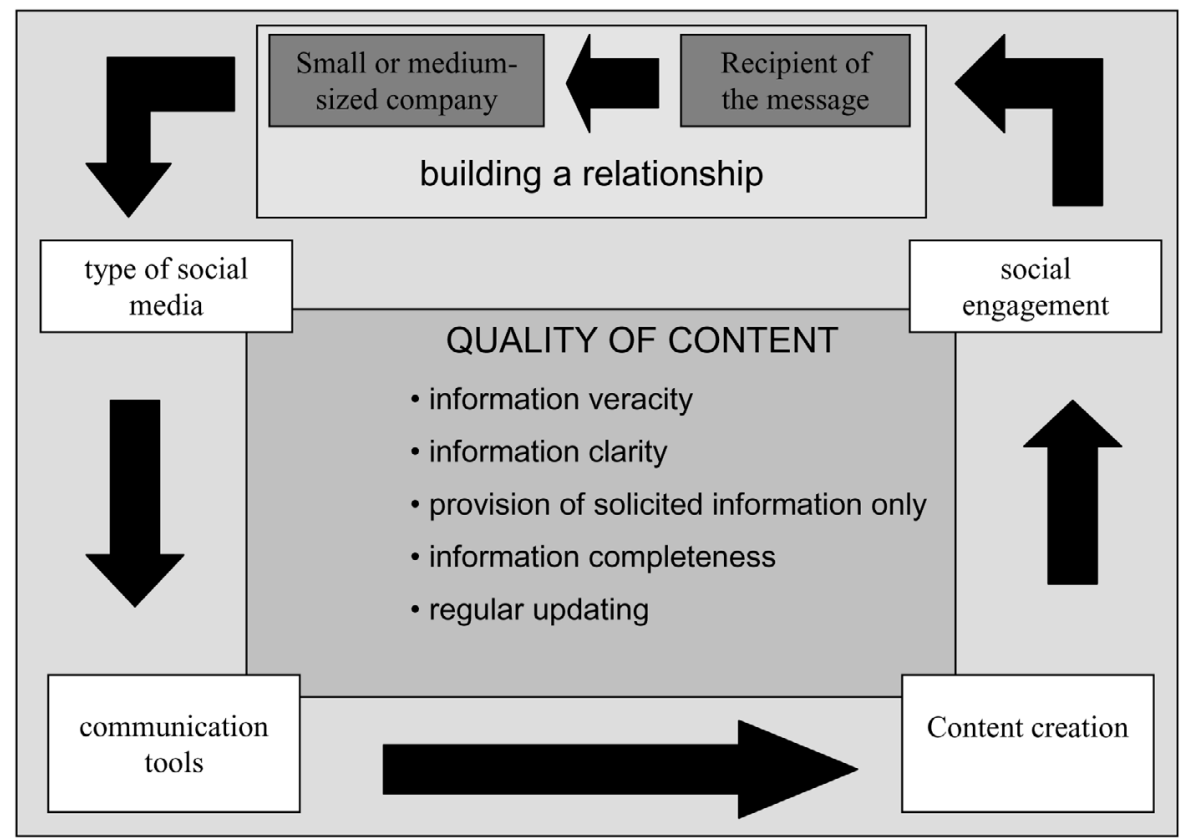

Source: own

"content creation", which is subject to quality. Content quality consists of information veracity, information clarity, provision of solicited information only, information completeness, and regular updating. At the same time, these attributes are the most important ones, derived from the research of the communication method. They form a part of the whole model as well, since these principles apply to the whole communication process and, therefore, they form the intersection in the model's centre.

Social engagement forms the fourth part of the communication model. It is a supplement added to a message; however, respondents in all researched groups consider it very important. Respondents named ecology, culture, ethics, and sport support the most important areas of social engagement.

In this point, the whole communication circle is closed; however, the process does not end here. As was already mentioned, this communication model does not have the exactly specified beginning. At the same time, it does not have the end. If the communication was successful, it led to the return contact with the company, which is the best state that could by achieved by the company. Based on such mutual communication, a relationship that leads to acquiring of a loyal customer is created. A loyal customer brings the biggest profit to the company. To the contrary, it there is no response from customers-users, an error occurred somewhere in the communication process. However, that must not discourage the company, but only bring an error in the process to attention. The company must react to it via a change and modify the whole communication process.

\section{Conclusion}

Based on national, as well as foreign literature search, it is possible to state that currently, no complex serious research exists on small or medium companies in confrontation with communication in social media in the Czech Republic environment. That is why this study was executed, in order to uncover possibilities 
of commercial communication with consumers via social media. The whole study contains a large amount of new information; however, its biggest contribution rests in proposal of the new communication model. This new communication model that was developed based on the empirical research reflects Czech specifics in social media. In its relatively simple form, the model captures the whole process that consists of the continuous information circulation. The model is based on four basic phases, through which information passes from a sender to a recipient. Each of these phases is supported by research and specified in detail in the study.

The study's contribution for companies. Communication via social media is by its nature a complex concept. On one side of the market there are trading companies that try to address consumers through communication channels. The market in which they move continuously sharpens, and the competition gets more intense, leading to a stronger effort to communicate with the consumer. On the other side there are customers with their expectations, needs and requests which vary from individual to individual. They use more and more frequently new communication channels from the comfort of their home. In the last five years social media have been the most progressively developing among these media. The output for small or medium-sized businesses is the ability to use the research findings in order to reach consumers. The original intention was directed to help small and medium-sized companies, but the research has not shown differences between using the communication model by small and medium-sized businesses and businesses with more employees. For this reason, the model is usable across the entire spectrum of businesses. Based on results, companies can apply targeted marketing and adjust their communication mix to the target group. This study is derived from theoretical foundations; however, despite that, it represents a big opportunity for small and medium companies to address respondents via social media in practice. The compiled communication model should serve the companies as instructions how to address potential customers. The model can be utilized if companies already have certain experience, as well as if they are only considering to enter the social media environment.
Currently, social media are already the essential part of companies' communication mix. However, it is necessary to realize that they represent only a part of the modern communication. Companies must neither underestimate, nor overestimate this communication channel. However, if the company wants to be successful, it should include social media in its regular communication portfolio where they belong.

At present it is necessary to rank social media as a separate information channel to the traditional communication media, which are the radio, TV, prints, external media and the Internet. For many people, the term social media is represented by Facebook, which is clearly dominant

in the CR. However, under this name can be included many other resources:

- Blogs, video blogs, microblogs (Twitter).

- Social networks (Facebook, MySpace, Linkedln, Google+).

- Wikis (Wikipedia, Google Knol).

- Social bookmark systems (Digg, Delicious, Jaggi).

- Shared Multimedia (YouTube, Flickr).

- Virtual worlds (Second Life, The Sims).

- Discussion forums, QaA portals (Yahoo! Answers).

It is then necessary to continue in the choice of instruments from the mentioned types of social media because they are also the first part of the set model. These tools are part of the second component of the presented model. After that there comes the creation of content supplemented by the current social aspects. The model has a great advantage in that when social media, the communication tools and content will change in the future, the model will always be functional since it is based on the constant circulation of information. The crucial aspect is the company's strategy to which all parts of the communication model are subject. When the strategy is changed, they can continuously change both a type of social media and communication tools and the content of the communication as it will follow.

\section{References}

[1] AD AGE. Marketers Buy Facebook More for Awareness than Likes or Leads. Ad Age Survey 2012 [online]. New York: Crain Communications Inc. [cit. 2012-06-05]. Available from: 
http://adage.com/article/digital/survey-marketerss-top-goal-face book-ads awareness/235841/.

[2] ANTLOVÁ, K., POPELÍNSKÝ, L. and TANDLER, J. Long term growth of SME from the view of ICT competencies and web presentations. E+M Ekonomie a Management. 2011, Vol. 13, Iss. 4, pp. 125-139. ISSN 1212-3609.

[3] BOUDA, T. Sociální média. Inflow [online]. 2009-08-06 [cit. 2012-05-09]. Available from: http://www.inflow.cz/socialni-media. ISSN 1802-9736. [4] BUSH, V.D., BUSH, A.J., CLARK, P. and BUSH, R.P. Girl Power and Word-of-Mouth Behavior in the Flourishing Sports Market. Journal of Consumer Marketing. 2006, Vol. 22, Iss. 5, pp. 257-264. ISSN 0736-3761.

[5] BUSINESSINFO. Kriteria komunikace na sociálních médiích [online]. Praha: CzechTrade, c2010. [cit. 2011-01-17]. Available from: http://www.businessinfo.cz/.

[6] DREZE, X. and HUSSHERR, F.X. Internet advertising: Is anybody watching? Journal of Interactive Marketing. 2003, Vol. 17, Iss. 4, pp. 8-23. ISSN 1094-9968.

[7] GIRARD, J. and BERTSCH, A. Exploring cross-cultural differences in social knowledge creation and exchange: A preliminary examination. International Journal of Management and Information Systems. 2001, Vol. 15, Iss. 1, pp. 97-104. ISSN 1546-5748.

[8] EUROMONITOR INTERNATIONAL. Quick Pulse: Consumers and Companies on Social Media [online]. 2012 [cit. 2012-08-30]. Available from: Business News: http://ebiz-tutorial.com/business-news/570-quick-pulse-consumers-and-companies-on-social-media.

[9] HOLLIS, N. Ten years of learning on how online advertising builds brands. Journal of Advertising Research. 2005, Vol. 45, Iss. 2, pp. 255-268. ISSN 0021-8499.

[10] CHATTERJEE, P., HOFFMAN, D.L. and NOVAK, T.P. Modeling the clickstream: Implications for web-based advertising efforts. Marketing Science. 2003, Vol. 22, Iss. 4, pp. 520-541. ISSN 0732-2399.

[11] IBM. IBM Institute for Business Value analysis [online]. CRM Study, 2011 [cit. 2011-12-02]. Available from: http://public.dhe.ibm.com/common/ ssi/ecm/en/gbe03391usen/GBE03391USEN.

[12] IMQQ. QQ international [online]. Peking: Tencent, c2012. [cit. 2012-05-01]. Available from: http://imqq.com/.

[13] KLEIN, L.R. and FORD, G.T. Consumer search for information in the digital age: An empirical study of prepurchase search for automobiles. Journal of Interactive Marketing. 2003, Vol. 17, Iss. 3, pp. 29-49. ISSN 1094-9968.

[14] KNIGHT, K. What's in a social network? Plenty, say marketers, politicians. BizReport [online]. Hellerup: BizReport, c2011 [cit. 2011-06-15]. Available from: http://www.bizreport.com/2011/ 06/whats-in-a-social-network-plenty-say-marketerspoliticians.html.

[15] KOTLER, P. and LEE, N.R. Social marketing: Influencing behaviors for good. 3rd ed. Thousand Oaks (CA): Sage publication Inc., 2008. ISBN 978-1-4129-8149-1.

[16] KOZEL, R., MYNÁR̆OVÁ, L. and SVOBODOVÁ, H. Moderní metody a techniky marketingového výzkumu. Praha: Grada Publishing, 2011. ISBN 978-80-247-3527-6.

[17] MANCHANDA, P., DUBE, J., KHIM, Y.G. and CHINTAGUNTA, P.K. The effect of banner advertising on internet purchasing. Journal of Marketing Research. 2006, Vol. 43, Iss. 1, pp. 98-108. ISSN 0022-2437.

[18] MELOUN, M. and MILITKÝ, M. Kompendium statistického zpracování dat: metody a řešené úlohy. 2. vyd. Praha: Academia, 2006. ISBN 80-200-1396-2.

[19] MILARDO, R.M. Families and Social Networks. Thousand Oaks (CA): Sage Publications, 1988. ISBN 80-8039-264-3.

[20] NEUGEBAUER, T. Nová pravidla písemné a elektronické komunikace. Praha: Computer Media s.r.o., 2009. ISBN 978-8074-020-11-7.

[21] NM INCITE. The Social marketer [online]. 2012. [cit. 2012-06-19]. Available from: //http://nmincite.com/blog/.

[22] NUNALLY, J.C., BERNSTEIN, I.H. Psychometric theory. 3rd ed. New York: McGraw Hill, 1994. ISBN 978-0-0704-7849-7.

[23] POMFFYOVÁ, M. Optimizing Of Communication Processes Management. E+M Ekonomie a Management. 2008, Vol. 9, Iss. 4, pp. 144-155. ISSN 1212-3609.

[24] SAUNDERS, M.N.K., LEWIS, P. and THORNHILL, A. Research Methods for Business Students. 3rd ed. New Jersey: Prentice Hall, 2002. ISBN 978-0-273-65804-7.

[25] SCOBLE. Tech geek blogger: Blog Archive What is social media? [online]. Scobleizer: 2007-0216 [cit. 2009-01-12]. Available from: http://scobleizer.com/2007/02/16/what-is-social-media/.

[26] SCOTT, D.M. The New Rules of Marketing and PR. New Jersey: John Wiley \& Sons, Inc., 2010. ISBN 978-0-470-54781-6. 
[27] SCHEIL, R. The Global Social Media Network / Blog [online]. Praha: 2009 [cit. 2009-01-12]. Available from: http://www.globalsocialmedianetwork.com/.

[28] SHERMAN, L. and DEIGHTON, J. Banner advertising: Measuring effectiveness and optimizing placement. Journal of Interactive Marketing. 2001, Vol. 15, Iss. 2, pp. 60-64. ISSN 1094-9968. [29] SOCIALBAKERS. Company offering monitoring and tracking tools for analysis of social networks that are used for comparing social media stats and metrics [online]. Liberec: Socialbakers, c2012 [cit. 2012-05-11]. Available from: http://www. socialbakers.com/facebook-statistics/czechrepublic.

[30] THACKERAY, R. and NEIGER, B.L. A multidirectional communication model: Implications for social marketing practice. Health Promotion Practice. 2009, Vol. 10, Iss. 2, pp. 171-175. ISSN 1524-8399.

[31] THACKERAY, R., NEIGER, B.L., HANSON C.L. and MCKENZIE J.F. Enhancing promotional strategies within social marketing programs: Use of web 2.0 social media. Health Promotion Practice. 2008, Vol. 9, Iss. 4, pp. 338-343. ISSN 1524-8399.

[32] THACKERAY, R. NEIGER, B.L. and KELLER, $H$. Integrating social media and social marketing: A four-step process. Health Promotion Practice. 2012, Vol. 13, Iss. 2, pp. 165-168. ISSN 1524-8399.
[33] VEJAČKA, M. Facebook advertising and its efficiency on the slovak market. E+M Ekonomie a Management. 2012, Vol. 15, Iss. 1, pp. 116-127. ISSN 1212-3609.

[34] VENKATESH, S. and HOLLINGER, M. Online and Mobile Advertising: Current Scenario, Emerging Trends, and Future Directions. MSI Report No. 07-206. Marketing Science Institute, 2007.

[35] VESCOVI, T. Internet communication: the Italian SME case. Corporate Communication: An International Journal. 2000, Vol. 5, Iss. 2, pp. 107-112. ISSN 1356-3289.

[36] WOMMA. Word of mouth 101: An introduction to word of mouth marketing. A womma white paper [online]. Chicago: Word of Mouth Marketing Association, c2009 [2009-01-15]. Available from: http://womma.org/womm101/.

Ing. Otakar Ungerman, Ph.D. Technical University of Liberec Faculty of Economics Department of Marketing and Trade otakar.ungerman@tul.cz

Ing. Světlana Myslivcová Technical University of Liberec Faculty of Economics Department of Marketing and Trade svetlana.myslivcova@tul.cz 


\section{Abstract}

\section{MODEL OF COMMUNICATION USABLE FOR SMALL AND MEDIUM-SIZED COMPANIES FOR THE CONSUMER COMMUNICATION IN SOCIAL MEDIA Otakar Ungerman, Světlana Myslivcová}

The subject of this report rests in small and medium companies that use social media for communication with their consumers, which is without a doubt one of the important methods of the current modern marketing communication. Competition keeps growing on the current market, and small or medium companies have increasingly more difficult position in establishing themselves against the international chains. If such companies wish to succeed in this struggle, they must utilize all means leading to creation of long-term relationships with their customers. Social media represent one way of building such relationship, since it is activity, creativity, idea, or thought, and not financial means, what matters. However, there is still a question regarding how companies should utilize social media so that they satisfy individual wishes and needs of customers and stay on the market. Proposal of a certain communication method standard that would provide small and middle companies with a general instructions how to build a relationship with a customer can be the solution. Therefore, this study's objective rests in a proposal of a marketing communication model that respect specifics of small or medium companies and social media. The communication model was built especially on identification of dimensions that are the most important in a user's perception of the social medium. At first, this study summarizes existing knowledge on utilization of the social media, communication modeling, and the current relationship of a sender and a recipient toward social communication. These concepts were subjected to the comparative analysis and summarized in the final synthesis. For the purpose of achieving the study's objective, empirical evaluation of social media users had been carried out. Data was evaluated using onedimension and multiple-dimension statistic analysis. A communication model that can be utilized by small or medium companies for communication with consumers using social media is proposed in the study's conclusion.

Key Words: Marketing communication, social media, communication model, consumer satisfaction, factor analysis, communication tools, relationship building.

JEL Classification: M31.

DOI: 10.15240/tul/001/2014-1-013 